\title{
Evaluation of antioxidant and anticancer properties of the seed extracts of Syzygium fruticosum Roxb. growing in Rajshahi, Bangladesh
}

Shafiqul Islam ${ }^{1 \dagger}$, Samima Nasrin ${ }^{1 \dagger}$, Muhammad Ali Khan², ASM Sakhawat Hossain ${ }^{1}$, Farhadul Islam³, Proma Khandokhar ${ }^{4}$, M Nurul Haque Mollah', Mamunur Rashid', Golam Sadik', Md Aziz Abdur Rahman ${ }^{1}$ and AHM Khurshid Alam ${ }^{1 *}$

\begin{abstract}
Background: The use of plants and their derived substances increases day by day for the discovery of therapeutic agents owing to their versatile applications. Current research is directed towards finding naturally-occurring antioxidants having anticancer properties from plant origin since oxidants play a crucial role in developing various human diseases. The present study was designed to investigate the antioxidant and anticancer properties of Sygygium fruticosum (Roxb.) (abbreviated as SF).

Methods: The dried coarse powder of seeds of SF was exhaustively extracted with methanol and the resulting crude methanolic extract (CME) was successively fractionated with petroleum ether, chloroform and ethyl acetate to get petroleum ether (PEF), chloroform (CHF), ethyl acetate (EAF) and lastly aqueous (AQF) fraction. The antioxidant activities were determined by several assays: total antioxidant capacity assay, DPPH free radical scavenging assay, hydroxyl radical scavenging assay, ferrous reducing antioxidant capacity and lipid peroxidation inhibition assay. The in vivo anticancer activity of SF was determined on Ehrlich's Ascite cell (EAC) induced Swiss albino mice.
\end{abstract}

Results: All the extractives showed strong antioxidant activities related to the standard. The total antioxidant capacity (TAC) of the fractions was in the following order: EAF>AQF>CME>PEF>CHF. The TAC of EAF at $320 \mathrm{\mu g} / \mathrm{mL}$ was $2.60 \pm 0.005$ which was significantly higher $(p<0.01)$ than that of standard catechin $(1.37 \pm 0.005)$. The ferrous reducing antioxidant capacity of the extracts was in the following order: EAF $>A Q F>C M E>A A>C H F>P E F$. In DPPH free radical scavenging assay, the $I C_{50}$ value of EAF was $4.85 \mu \mathrm{g} / \mathrm{mL}$, whereas that of BHT was $9.85 \mu \mathrm{g} / \mathrm{mL}$. In hydroxyl radical scavenging assay and lipid peroxidation inhibition assay, the EAF showed the most potent inhibitory activity with $\mathrm{IC}_{50}$ of 43.3 and $68.11 \mu \mathrm{g} / \mathrm{mL}$, respectively. The lipid peroxidation inhibition assay was positively correlated $(p<0.001)$ with both DPPH free radical scavenging and hydroxyl radical scavenging assay. The total phenolic contents of SF were also positively correlated $(p<0.001)$ with DPPH free radical scavenging, hydroxyl radical scavenging and lipid peroxidation inhibition assay. Based on antioxidant activity, EAF was selected for cytotoxic assay and it was found that EAF inhibited 67.36\% $(p<0.01)$ cell growth at a dose of $50 \mathrm{mg} / \mathrm{kg}$ (ip) on day six of EAC cell incubation.

Conclusions: Our results suggest that EAF of seeds of SF possess significant antioxidant and moderate anticancer properties. Seeds of SF may therefore be a good source for natural antioxidants and a possible pharmaceutical supplement.

Keywords: Syzygium fruticosum Roxb, Myrtaceae, Free radicals, Polyphenolics, Antioxidant activity, Anticancer activity

\footnotetext{
* Correspondence: khurshid.jaist@gmail.com

${ }^{\dagger}$ Equal contributors

'Department of Pharmacy, University of Rajshahi, Rajshahi 6205, Bangladesh

Full list of author information is available at the end of the article
} 


\section{Background}

It is increasingly being realized that many of today's diseases are due to the oxidative stress (OS) that results from an imbalance between formation and neutralization of prooxidants. OS is initiated by free radicals like hydroxyl, peroxyl and superoxide radicals, which become stable through electron pairing with biological macromolecules such as proteins, lipids and DNA in healthy human cells and cause protein and DNA damage along with lipid peroxidation. The damage caused by OS has been implicated as a potential contributor to the pathogenesis of cancer, diabetes, atherosclerosis, cardiovascular diseases, ageing and inflammatory diseases [1,2]. The damage can become more widespread due to weakened cellular antioxidant defense systems. All biological systems have antioxidant defense mechanism that protects against oxidative damages and repairs enzymes to remove damaged molecules. However, this natural antioxidant defense mechanism can be inefficient; hence dietary intake of antioxidant is important.

Antioxidants are substances that prevent damage to cells caused by free radicals by supplying electron to these free radicals. This stabilizes the molecule, thus preventing damage to other cells. Antioxidants also turn free radicals into waste by products, and they eventually get eliminated from the body. However, consumption of fruits and vegetables is known to lower the risk of several diseases, such as cancer, cardiovascular diseases and stroke caused by OS [3], and such health benefits are mainly imposed due to the presence of phytochemicals, such as polyphenols, carotenoids and vitamin E and C [4].

Although the phenolic compounds are commonly found in both edible and non edible herbs, cereals, fruits, vegetables, oils, spices and other plant materials [5,6], scientific information on antioxidant properties of endemic plants, limited to certain regions and known only by local populations, is still rather scarce. Therefore, the assessment of such properties remains an interesting and useful task, particularly to find new promising sources of natural antioxidants for functional foods and/or nutraceuticals [6,7].

Syzygium fruticosum (family Myrtaceae) is one of 1100 species in the genus Syzygium and is widely spread in India, Myanmar, China, Thailand and Bangladesh [8]. It is used in some countries as folk remedy for the treatment of diabetes, stomachic, and bronchitis $[9,10]$. To our knowledge from literatures there is no work about phytochemical contents and biological activities of Syzygium fruticosum. However, literature review on Syzygium genus showed that the various species of Syzygium possess a variety of biological activities. The leaves of Syzygium cumini showed antioxidant, anti-allergic, anti-inflammatory and analgesic propertie [9,10]. The seed extracts of $S$. aromaticum, S. jambos and S. aqueum and the fruit and bark extracts of $S$. aromaticum showed antidiabetic, antihyperlipidemic, gastroprotective, antioxidant, antiallergic, and analgesic activities [10-14].

To reveal the potential of medicinal plants available in Bangladesh, as a part of our ongoing research [15], we selected Syzygium fruticosum as the information of medicinal values of $S$. fruticosum is still lacking in the literature. Therefore, this study was carried out to enrich the information of the medicinal property of S. fruticosum in terms of antioxidant and anticancer as well as its polyphenoic contents in the literature.

\section{Methods}

\section{Collection of plant materials}

Seeds of SF were collected from Rajshahi University Campus, Rajshahi, Bangladesh in May, 2011 and were identified by an expert taxonomist at National Herbarium, Dhaka, Bangladesh where a voucher specimen was deposited (Accession number: 1326). Plant materials were then washed with fresh water to remove dirty materials and were shade dried for several days with occasional sun drying. The dried materials were ground into coarse powder by grinding machine, and the materials were stored at room temperature for future use.

\section{Preparation of extract}

About 500 gm of dried powdered plant materials were taken in an amber colored extraction bottle (2.5 liter capacity) and the materials were soaked with methanol $(1 \mathrm{~L} \times 3$ times $)$. The sealed bottle was kept for 7 days with occasional shaking and stirring. The combined extracts were filtered through cotton and then Whatman No.1 filter papers and were concentrated with a rotary evaporator under reduced pressure at $45^{\circ} \mathrm{C}$ to afford 40 gm crude seed extract. The extract was then fractionated by pet-ether, chloroform, ethyl acetate and finally with water to obtain petroleum ether fraction (PEF, 13.54 gm), chloroform fraction (CHF, $8.28 \mathrm{gm}$ ), ethyl acetate fraction (EAF, $7.68 \mathrm{gm}$ ) and aqueous fraction (AQF, $10.50 \mathrm{gm}$ ).

\section{Chemicals}

1,1-diphenyl-2-picrylhydrazyl (DPPH), potassium ferricyanide, potassium acetate, phosphate buffer, catechin (CA), ferrous ammonium sulphate, butylated hydroxytoluene (BHT), gallic acid (GA), ascorbic acid (AA), $\mathrm{AlCl}_{3}$, Trichloro acetic acid (TCA), sodium phosphate, ammonium molybdate, tannic acid, quercetin (QU), DMSO, EDTA, thiobarbituric acid (TBA), acetyl acetone and $\mathrm{FeCl}_{3}$ were purchased from Sigma Chemical Co. (St. Louis, MO, USA); vanillin was obtained from BDH; Folin-Ciocalteus's phenol reagent and sodium carbonate were obtained from Merck (Damstadt, Germany). 


\section{Estimation of total phenolics}

Total phenolic contents of the extracts were determined by the modified Folin-Ciocalteu method described by Wolfe et al. [16]. An aliquot of the extracts/standard was mixed with $2 \mathrm{ml}$ Folin-Ciocalteu reagent (previously diluted with water $1: 10 \mathrm{v} / \mathrm{v})$ and $2 \mathrm{ml}(75 \mathrm{~g} / \mathrm{l})$ of sodium carbonate. The tubes were vortexed for 15 seconds and allowed to stand for 20 minutes at $25^{\circ} \mathrm{C}$ for color development. Absorbance was then measured at $760 \mathrm{~nm}$ UV-spectrophotometer (Shimadzu, USA). Samples of extracts/standard were evaluated at a final concentration of $0.1 \mathrm{mg} / \mathrm{mL}$. Total phenolic contents were expressed in terms of gallic acid equivalent, GAE (standard curve equation: $\left.y=0.011 x+0.066, R^{2}=0.998\right), \mathrm{mg}$ of $\mathrm{GA} / \mathrm{g}$ of dry extract.

\section{Determination of total flavonoids}

Total flavonoids were estimated using the method described by Ordonez et al. [17]. To $0.5 \mathrm{ml}$ of samples/ standard, $1.5 \mathrm{ml}$ of methanol, $100 \mu \mathrm{l}$ of $10 \%$ aluminum chloride, $100 \mu \mathrm{l}$ of $1 \mathrm{M}$ potassium acetate solution and $2.8 \mathrm{ml}$ of distilled water was added. After one hour 30 minutes of incubation at room temperature (RT), the absorbance was measured at $420 \mathrm{~nm}$. The samples/ standard was evaluated at a final concentration of 0.1 $\mathrm{mg} / \mathrm{mL}$. Total flavonoid contents were expressed in terms of catechin equivalent, CAE (standard curve equation: $\left.y=0.003 x+0.022, R^{2}=0.997\right), \mathrm{mg}$ of $\mathrm{CA} / \mathrm{g}$ of dry extract.

\section{Determination of total flavonols}

Total flavonols in the plant extracts were estimated using the method of Kumaran and Karunakaran [18]. To $2.0 \mathrm{ml}$ of sample/standard, $2.0 \mathrm{ml}$ of $2 \% \mathrm{AlCl}_{3}$ ethanol and $3.0 \mathrm{ml}$ $(50 \mathrm{~g} / \mathrm{L})$ sodium acetate solutions were added. The absorption at $440 \mathrm{~nm}$ was read after 2.5 hours at $20^{\circ} \mathrm{C}$. Extractives/standard were evaluated at a final concentration of $0.1 \mathrm{mg} / \mathrm{mL}$. Total content of flavonols was expressed in terms of quercetin equivalent, QUE (standard curve equation: $\left.y=0.0255 x+0.0069, R^{2}=0.9995\right), \mathrm{mg}$ of $\mathrm{QU} / \mathrm{g}$ of dry extract.

\section{Determination of total proanthocyanidins}

Determination of content of proanthocyanidins was based on the procedure reported by Sun et al. [19]. A volume of $0.5 \mathrm{ml}$ of $0.1 \mathrm{mg} / \mathrm{mL}$ of extracts/standard solution was mixed with $3 \mathrm{ml}$ of $4 \%$ vanillin-methanol solution and $1.5 \mathrm{ml}$ hydrochloric acid; the mixture was allowed to stand for 15 minutes. The absorbance was measured at $500 \mathrm{~nm}$. Samples/standard was evaluated at a final concentration of $0.1 \mathrm{mg} / \mathrm{mL}$. Total content of proanthocyanidins was expressed in terms of catechin equivalent, CAE (standard curve equation: $\left.y=0.567 x-0.024, R^{2}=0.9801\right), m g$ of $C A / g$ of dry extract.

\section{Determination of antioxidant activity Determination of total antioxidant capacity}

Total antioxidant capacity (TAC) of samples/standard was determined by the method reported by Prieto et al. [20] with some modifications. $0.5 \mathrm{ml}$ of samples/standard at different concentrations was mixed with $3 \mathrm{ml}$ of reaction mixture containing $0.6 \mathrm{M}$ sulphuric acid, 28 $\mathrm{mM}$ sodium phosphate and $1 \%$ ammonium molybdate into the test tubes. The test tubes were incubated at $95^{\circ} \mathrm{C}$ for 10 minutes to complete the reaction. The absorbance was measured at $695 \mathrm{~nm}$ using a spectrophotometer against blank after cooling at RT. CA was used as standard. A typical blank solution contained $3 \mathrm{ml}$ of reaction mixture and the appropriate volume of the same solvent used for the samples/standard were incubated at $95^{\circ} \mathrm{C}$ for 10 minutes and the absorbance was measured at $695 \mathrm{~nm}$. Increased absorbance of the reaction mixture indicated increase total antioxidant capacity.

\section{Determination of ferrous reducing antioxidant capacity}

The ferrous reducing antioxidant capacity of samples/ standard was evaluated by the method of Oyaizu [21]. $0.25 \mathrm{ml}$ samples/standard solution at different concentrations, $0.625 \mathrm{ml}$ of potassium buffer $(0.2 \mathrm{M})$ and $0.625 \mathrm{ml}$ of $1 \%$ potassium ferricyanide $\left[\mathrm{K}_{3} \mathrm{Fe}(\mathrm{CN})_{6}\right]$ solution were added into the test tubes. The reaction mixture was incubated for 20 minutes at $50^{\circ} \mathrm{C}$ to complete the reaction. Then $0.625 \mathrm{ml}$ of $10 \%$ TCA solution was added into the test tubes. The total mixture was centrifuged at $3000 \mathrm{rpm}$ for 10 minutes. After which, $1.8 \mathrm{ml}$ supernatant was withdrawn from the test tubes and was mixed with $1.8 \mathrm{ml}$ of distilled water and $0.36 \mathrm{ml}$ of $0.1 \% \mathrm{FeCl}_{3}$ solution. The absorbance of the solution was measured at $700 \mathrm{~nm}$ using a spectrophotometer against blank. A typical blank solution contained the same solution mixture without plant extracts/standard was also incubated under the same condition, and the absorbance of the blank solution was measured at $700 \mathrm{~nm}$. Increased absorbance of the reaction mixture indicated increase reducing capacity.

\section{DPPH free radical scavenging assay}

Free radical scavenging activity was determined by DPPH radical scavenging assay as described by Choi et al. [22]. A solution of $0.1 \mathrm{mM}$ DPPH in methanol was prepared and $2.4 \mathrm{ml}$ of this solution was mixed with $1.6 \mathrm{ml}$ of extractives in methanol at different concentrations. The reaction mixture was vortexed thoroughly and left in the dark at RT for 30 minutes. The absorbance of the mixture was measured spectrophotometrically at $517 \mathrm{~nm}$. BHT was used as reference standard. Percentage DPPH radical 
scavenging activity was calculated by the following equation:

$$
\begin{aligned}
& \text { (\% DPPH radical scavenging activity) } \\
& \quad=\left\{\left(\mathrm{A}_{\mathrm{o}}-\mathrm{A}_{1}\right) / \mathrm{A}_{\mathrm{o}}\right\} \times 100
\end{aligned}
$$

where $A_{0}$ is the absorbance of the control, and $A_{1}$ is the absorbance of the extractives/standard. Then $\%$ of inhibition was plotted against concentration, and from the graph $\mathrm{IC}_{50}$ was calculated.

\section{Hydroxyl radical scavenging activity}

Hydroxyl radical scavenging activity of the extractives/ standard was determined by the method of Klein et al. [23] with a slight modification. $0.5 \mathrm{ml}$ of extractives/ standard at different concentrations was taken in different test tubes. $1 \mathrm{ml}$ of Fe-EDTA solution $(0.13 \%$ ferrous ammonium sulphate and $0.26 \%$ EDTA), $0.5 \mathrm{ml}$ of $0.018 \%$ EDTA solution, $1 \mathrm{ml}$ of $0.85 \%$ DMSO solution and $0.5 \mathrm{ml}$ of $22 \%$ AA were added into each of the test tubes. The test tubes were capped tightly and warm at $85^{\circ} \mathrm{C}$ for 15 minutes into the water bath. After incubation, the test tubes were uncapped and $0.5 \mathrm{ml}$ ice cold TCA (17.5\%) was added to each of test tubes immediately. Three $\mathrm{ml}$ of nash reagent $(7.5 \mathrm{gm}$ of ammonium acetate, $300 \mu \mathrm{l}$ glacial acetic acid and $200 \mu \mathrm{l}$ acetyl acetone were mixed and made up to 100 $\mathrm{ml}$ ) was added into all of the test tubes and incubated at RT for 15 minutes. Absorbance was taken at 412 $\mathrm{nm}$ wave length by UV-spectrophotometer. Percentage hydroxyl radical scavenging activity was calculated by the following equation:

$$
\begin{aligned}
& \% \text { hydroxyl radical scavenging activity } \\
& \quad=\left\{\left(\mathrm{A}_{\mathrm{o}}-\mathrm{A}_{1}\right) / \mathrm{A}_{\mathrm{o}}\right\} \times 100
\end{aligned}
$$

where $A_{0}$ is the absorbance of the control, and $A_{1}$ is the absorbance of the extractives/standard. Then \% of inhibition was plotted against concentration, and from the graph $\mathrm{IC}_{50}$ was calculated.

\section{Lipid peroxidation inhibition assay}

The lipid peroxidation inhibition assay was determined according to the method described by Liu et al. [24] with a slight modification. Excised rat liver was homogenized in buffer and then centrifuged to obtain liposome. 0.5 $\mathrm{ml}$ of supernatant, $100 \mu \mathrm{l} 10 \mathrm{mM} \mathrm{FeSO}{ }_{4}, 100 \mu \mathrm{l} 0.1 \mathrm{mM}$ $\mathrm{AA}$ and $0.3 \mathrm{ml}$ of extractives/standard at different concentrations were mixed to make the final volume $1 \mathrm{ml}$. The reaction mixture was incubated at $37^{\circ} \mathrm{C}$ for $20 \mathrm{mi}-$ nutes. One $\mathrm{ml}$ of (28\%) TCA and $1.5 \mathrm{ml}$ of (1\%) TBA was added immediately after heating. Finally, the reaction mixture was again heated at $100^{\circ} \mathrm{C}$ for $15 \mathrm{mi}-$ nutes and cooled at RT. After cooling, the absorbance was taken at $532 \mathrm{~nm}$. Percentage inhibition of lipid peroxidation was calculated by the following equation:

$$
\begin{aligned}
& \% \text { lipid peroxidation inhibition } \\
& \quad=\left\{\left(\mathrm{A}_{\mathrm{o}}-\mathrm{A}_{1}\right) / \mathrm{A}_{\mathrm{o}}\right\} \times 100
\end{aligned}
$$

where $A_{0}$ is the absorbance of the control, and $A_{1}$ is the absorbance of the extractives/standard.

Then $\%$ of inhibition was plotted against concentration, and $\mathrm{IC}_{50}$ was calculated from the graph.

\section{Determination of anticancer activity Cell growth inhibition}

In vivo tumor cell growth inhibition was carried out by the method previously described by Sur et al. [25]. Protocol used in this study for the use of mice as animal model for cancer research was approved by the Institutional Animal, Medical Ethics, Biosafety and Biosecurity Committee (IAMEBBC) for Experimentations on Animal, Human, Microbes and Living Natural Sources (225/320-IAMEBBC/ IBSc), Institute of Biological Sciences, University of Rajshahi, Bangladesh.

For this study, 4 groups of mice (6 in each group) were used. For therapeutic evaluation, $14 \times 10^{5}$ Ehrlich's Ascites cells (EAC)/mouse was inoculated into each group of mice on the first day. Treatment was started after 24 hours of EAC inoculation and continued for 5 days. Group 1 to 2 received the test compound at doses $25 \mathrm{mg} / \mathrm{kg}$ and $50 \mathrm{mg} / \mathrm{kg}$, respectively per day per mouse. In each case, the volume of the test solutions injected intraperitoneally (i.p.) was $0.1 \mathrm{ml} /$ day per mouse. Group 3 received standard bleomycin $(0.3 \mathrm{mg} / \mathrm{kg}$, i.p) and were considered as positive control. Finally the group 4 mice were treated with the vehicle (normal saline) and were considered as untreated control. The mice were sacrificed on the $6^{\text {th }}$ day after transplantation and tumor cells were collected by repeated i.p. wash with $0.9 \%$ saline. Viable tumor cells per mouse of the treated group were compared with those of control.

The cell growth inhibition was calculated using the following formula:

$$
\% \text { Cell growth inhibition }=\left(1-\frac{T w}{C w}\right) \times 100
$$

where, $\mathrm{Tw}=$ Mean of number of tumor cells of the treated group of mice and $\mathrm{Cw}=$ Mean of number of tumor cells of the control group of mice.

\section{Statistical analysis}

All analyses were carried out in triplicates. Data were presented as mean \pm SD. To evaluate significant relationships between experimental parameters by correlation and regression analysis, the $F$ - and $t$-tests $(p<0.001)$ were used. Free R-software version 2.15.1 (http://www.r-project.org/) 
and Microsoft Excel 2007 (Roselle, IL, USA) were used for the statistical and graphical evaluations.

\section{Results}

Determination of TAC and ferrous reducing antioxidant capacity

The TAC of CME and its four fractions of seeds of SF were shown in Figure 1A. CME of seeds of SF showed higher antioxidant activity compared to reference standard $\mathrm{CA}$ at all the concentrations. The absorbance of CME, PEF, CHF, EAF, AQF, and standard CA were 1.90, $2.21,0.96,2.60,1.49$ and 1.37 , respectively at $320 \mu \mathrm{g} / \mathrm{ml}$. The TAC of EAF was significantly higher $(p<0.01)$ than standard CA. The extractives were found to increase the total antioxidant activity with the increasing concentration of the extracts.

The Ferrous reducing antioxidant capacity of CME and it's four fractions are shown in Figure 1B. At $160 \mu \mathrm{g} / \mathrm{ml}$, the absorbance of CME, PEF, CHF, EAF, AQF, and standard AA were 2.77, 1.28, 2.24, 2.98, 2.89 and 2.32, respectively. A higher absorbance indicates a higher reducing power, hence CME, EAF and AQF showed higher reducing activity than standard AA. The ferrous reducing capacity of EAF was significantly higher $(p<0.01)$ than standard AA. On the other hand, PEF and CHF had mild to moderate iron reducing capacity. The reducing activity increased with the increasing concentration of the extracts.

\section{DPPH radical scavenging activity}

Figure 2A showed free radical scavenging activity of the CME and its four fractions. At a concentration of $25 \mu \mathrm{g} / \mathrm{ml}$, the scavenging activity of the CME, EAF and AQF were 95.95, 95.68 and $93.44 \%$, respectively, while at the same concentration, the activity of BHT was $88.51 \%$. Thus, CME, EAF and AQF exhibited significant free radical scavenging activity (Figure 2A). The scavenging activity of the PEF and CHF was in moderate level when compared with BHT (Figure 2A). The $\mathrm{IC}_{50}$ of CME, PEF, CHF, EAF and AQF were 9.90, 63.0, 23.7, 4.85 and
$10.0 \mu \mathrm{g} / \mathrm{ml}$, respectively. The $\mathrm{IC}_{50}$ of $\mathrm{BHT}$ was 9.85 $\mu \mathrm{g} / \mathrm{ml}$, which was almost double than the $\mathrm{IC}_{50}$ of EAF $(4.85 \mu \mathrm{g} / \mathrm{ml})$. The inhibitory activity of different extractives and BHT were in the following order: EAF > BHT > $\mathrm{CME}>\mathrm{AQF}>\mathrm{CHF}>\mathrm{PEF}$. Our results revealed that the EAF had higher scavenging activity than that of other extractives, even higher than BHT and CME and AQF had similar activity with BHT.

\section{Hydroxyl radical scavenging activity}

At a concentration of $150 \mu \mathrm{g} / \mathrm{ml}$, the scavenging activity of CME and its four fractions PEF, CHF, EAF and AQF reached $88.27,51.00,57.83,87.13$ and $63.90 \%$, respectively; while at the same concentration, the activity of $\mathrm{AA}$ was $84.24 \%$ (Figure 2B). The $\mathrm{IC}_{50}$ of $\mathrm{CME}$, PEF, CHF, EAF, AQF and AA were 50.23, 145.27, 133.43, 43.31, 124.61 and $32.11 \mu \mathrm{g} / \mathrm{ml}$, respectively. The result demonstrates that CME and EAF significantly scavenged hydroxyl radicals when compared with standard AA.

\section{Lioid peroxidation inhibition assay}

The lipid peroxides scavenging activity of CME of seeds of SF was investigated and compared with standard CA. At a concentration of $150 \mu \mathrm{g} / \mathrm{ml}$, the scavenging activity of CME and its fractions PEF, CHF, EAF and AQF were $78.20,55.36,53.99,82.63$ and $66.10 \%$, respectively; whereas the activity of CA was $80.54 \%$ (Figure $3 \mathrm{~A}$ ). The EAF exhibited higher activity than other extractives, even though higher than standard $\mathrm{CA}$. The $\mathrm{IC}_{50}$ of CME, PEF, CHF, EAF and AQF were 71.50, 136.34, $136.21,68.11$ and $100.31 \mu \mathrm{g} / \mathrm{ml}$, respectively; on the other hand, the $\mathrm{IC}_{50}$ of $\mathrm{CA}$ was 58.5 (Figure 3B). Significant correlations $(p<0.001)$ were observed between \% lipid peroxidation inhibition and \% hydroxyl radical scavenging (Figure 4).

Total phenolic, flavonoids, flavonol and proanthocyanidin contents

Table 1 shows the total polyphenols contents in the CME and its four fractions: PEF, CHF, EAF and AQF.
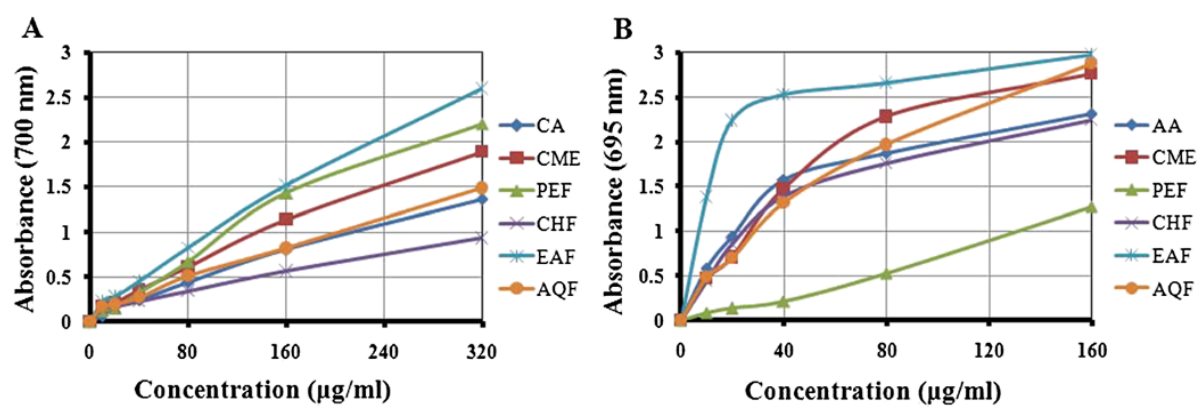

Figure 1 Determination of (A) total antioxidant capacity and (B) ferrous reducing antioxidant capacity of CME and its various fractions (PEF, CHF, EAF and AQF). Data expressed as mean $\pm \mathrm{SD}(n=3, p<.05)$ for all tested dosages. 

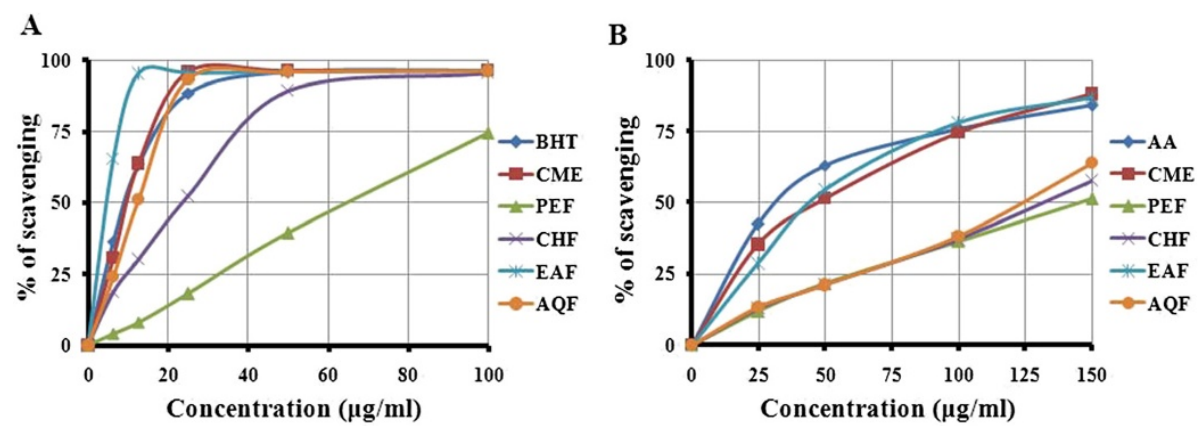

Figure 2 Determination of (A) DPPH radical scavenging activity and (B) $\mathrm{OH}$ radical scavenging activity of CME and its various fractions (PEF, CHF, EAF and AQF). Data expressed as mean $\pm \mathrm{SD}(n=3, p<.05)$ for all tested dosages.

Strong correlation $(p<0.001)$ of total phenolic content of the extractives with free radical $\left({ }^{\circ} \mathrm{OH}\right)$ scavenging efficiency and \% lipid peroxidation inhibition were observed (Figure 5).

\section{Tumor cell growth inhibition}

Since EAF showed the strongest antioxidant activity in all antioxidant tests, it was chosen for in vivo tumor cell growth inhibition at various doses $(25 \mathrm{mg} / \mathrm{kg}$ and $50.0 \mathrm{mg} / \mathrm{kg}$, i.p). Maximum cell growth inhibition (67.36\%, $p<0.01$ ) was found after treatment with EAF at dose $50.0 \mathrm{mg} / \mathrm{kg}$ (i.p) on day six of tumor inoculation. On the other hand, standard bleomycin at dose $0.3 \mathrm{mg} / \mathrm{kg}$ i.p inhibited the tumor cell growth by 83.81\% (Table 2). This result implies that the EAF had moderate anticancer activity, and the plant might therefore be considered as an effective source of active chemopreventive agents.

\section{Discussion}

\section{Total antioxidant capacity}

The total antioxidant potentials of seeds of SF extracts were estimated from their ability to reduce the reduction of Mo (VI) to Mo (V) and subsequent formation of a green phosphate/Mo (V) complex at acidic $\mathrm{pH}$. The reducing ability of the extractives was in the range of $0.94 \pm 0.002-2.60 \pm 0.005 \mu \mathrm{m}$ green phosphate/Mo (V) (Figure 1A). All the fractions showed a good total antioxidant activity, which was concentration-dependent. The antioxidant activity of EAF was significantly higher $(p<.05)$ than standard antioxidant. The antioxidant capacity may be attributed to their chemical composition and phenolic content. Jayaprakasha et al. [26] indicated that the total antioxidant activity of citrus was due to the presence of phenolics, flavonoids and ascorbic acid.

\section{Ferrous reducing antioxidant capacity}

Reducing power is also widely used in evaluating antioxidant activity of plant polyphenols. The reducing power is generally associated with the presence of reductones, which exert antioxidant action by breaking the free radical chains by donating a hydrogen atom. In this assay, the presence of reductants in the antioxidant sample causes the reduction of the $\mathrm{Fe}^{3+} /$ ferricyanide complex to the $\mathrm{Fe}^{2+} /$ ferrous form, so the reducing power of the sample can be monitored by measuring the formation of Perl's Prussian blue at 700 $\mathrm{nm}$ [27]. The reducing ability of the extractives was in the range of $1.47 \pm 0.004-2.98 \pm 0.002 \mu \mathrm{m} \mathrm{Fe}(\mathrm{II}) / \mathrm{g}$. The EAF exhibited strong reducing power and was higher
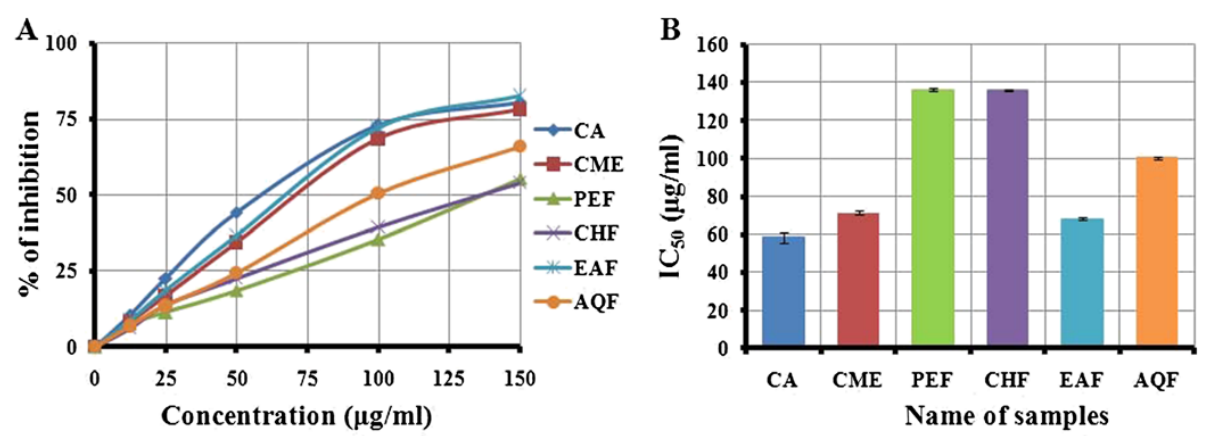

Figure 3 Determination of (A) lipid peroxidation inhibition of CME and its various fractions (PEF, CHF, EAF and AQF) and (B) IC 50 of CME and its various fractions (PEF, CHF, EAF and AQF) determined from lipid peroxidation inhibition assay. Data expressed as mean \pm $\mathrm{SD}(n=3, p<.05)$ for all tested dosages. 

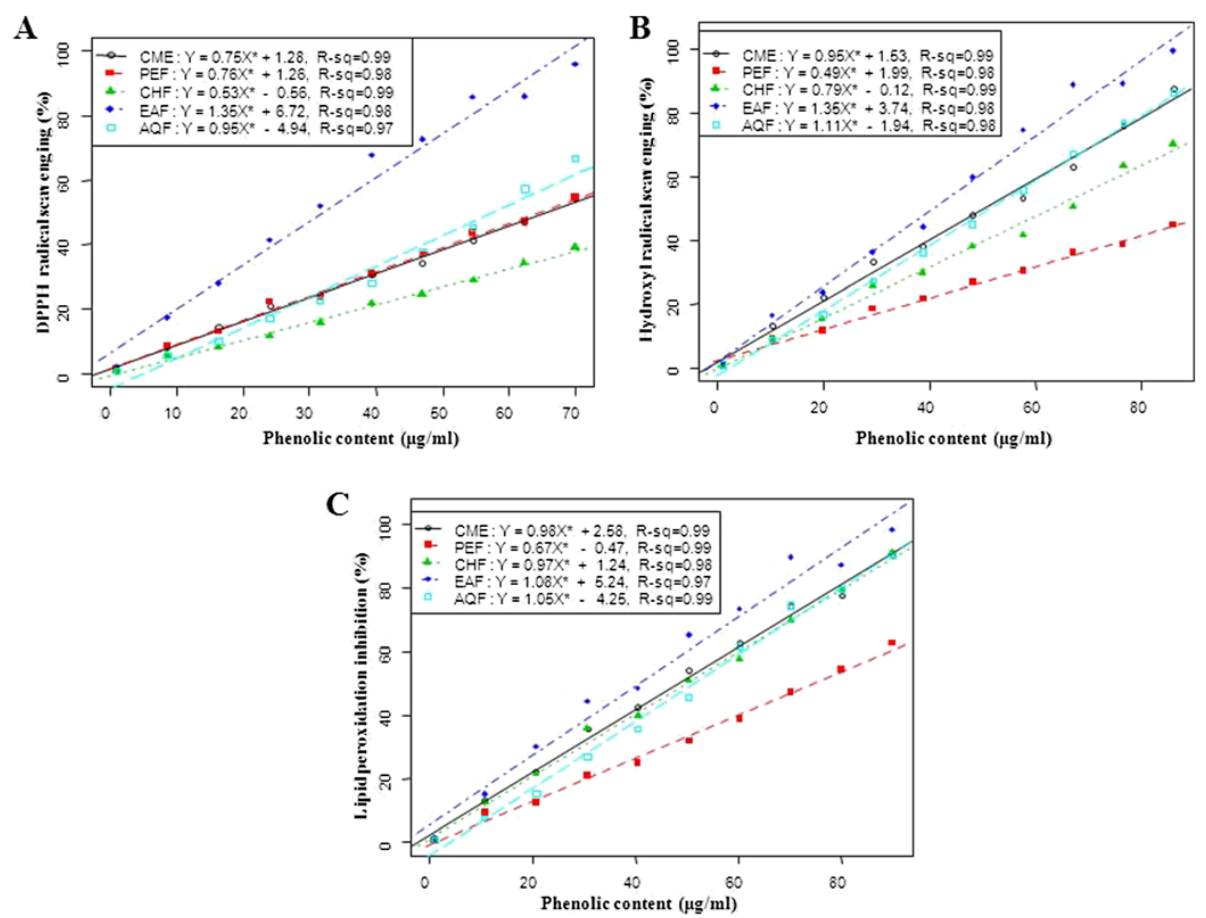

Figure 4 Relationship of total phenolic contents with (A) \% DPPH free radical scavenging, (B) \% hydroxyl radical scavenging activity and $(C) \%$ lipid peroxidation inhibition. Data expressed as mean \pm SD $(n=3, p<.001)$.

than other fractions, even significantly higher $(p<.05)$ than AA as shown in Figure 1B. The reducing power of EAF is probably due to the presence of phenolic compounds which might act as electron donors.

\section{DPPH radical scavenging activity}

The effect of antioxidants on DPPH radicals is thought to be due to their hydrogen donating ability [22]. Radical scavenging activities are very important to prevent the deleterious role of free radical in different diseases including cancer. DPPH free radical scavenging is an accepted mechanism by which antioxidants act to inhibit lipid peroxidation. This method has been used extensively to predict antioxidant activities because of the relatively short time required for analysis. The DPPH radical scavenging activity of all the fractions from SF seeds increased with increase in fraction concentration (Figure $2 \mathrm{~A}$ ). The $\mathrm{IC}_{50}$ of EAF was significantly higher $(p<.01)$ than that of other fractions and BHT with the order of EAF > BHT > $\mathrm{CME}>\mathrm{AQF}>\mathrm{CHF}>\mathrm{PEF}$. It has been found that phenolics, flavonoids and tocopherols reduce the DPPH radicals by their hydrogen donating ability $[28,29]$. The results obtained in this investigation reveal that all the fractions from SF seeds are free radical scavengers and able to react with the DPPH radical, which might be attributed to their electron donating ability.

\section{Hydroxyl radical scavenging activity}

The mutagenic capacity of free radicals is due to the direct interactions of hydroxyl radicals with DNA and therefore playing an important role in cancer formation [30]. Hydroxyl radicals can be generated by biochemical reaction. Superoxide radical is converted by superoxide dismutase to hydrogen peroxide, which can subsequently produce extremely reactive hydroxyl radicals in the

Table 1 Polyphenol contents of CME and its various fractions: PEF, CHF, EAF and AQF

\begin{tabular}{llllll}
\hline Polyphenols & CME & PEF & CHF & EAF & AQF \\
\hline Phenolics $^{a}$ & $301.63 \pm 4.36^{1}$ & $17.56 \pm 1.41$ & $118.13 \pm 1.61$ & $526.22 \pm 1.55$ & $266.88 \pm 2.78$ \\
Flavonoids $^{b}$ & $219.88 \pm 15.17$ & $152.13 \pm 6.34$ & $128.21 \pm 9.38$ & $612.75 \pm 5.37$ & $185.71 \pm 11.35$ \\
Flavonols $^{c}$ & $119.38 \pm 1.24$ & $185.48 \pm 1.19$ & $149.01 \pm 2.78$ & $220.38 \pm 1.26$ & $132.54 \pm 1.77$ \\
Proanthocyanidins $^{b}$ & $10.32 \pm 1.31$ & $12.36 \pm 0.04$ & $11.94 \pm 0.25$ & $44.68 \pm 0.05$ & $33.33 \pm 0.07$ \\
\hline
\end{tabular}

NB: ${ }^{1}$ Each value is the average of three analyses \pm standard deviation. $a, b$ and $c$ expressed in terms of GAE, CAE and QUE, respectively (mg of GA, CA and QU/g of dry extract, respectively). 
A

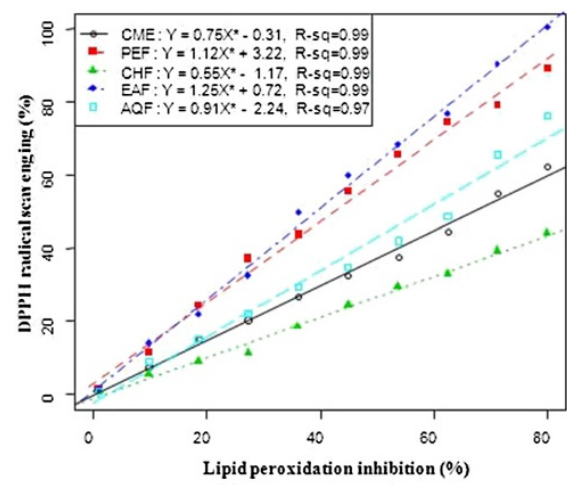

B

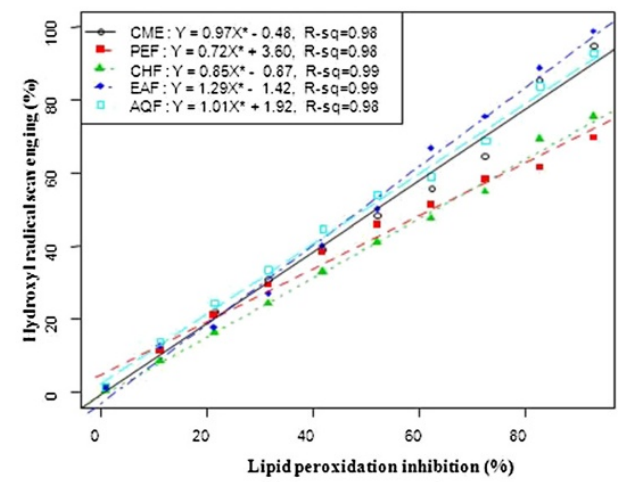

Figure 5 Relationship of \% lipid peroxidation inhibition with (A) \% DPPH free radical scavenging and (B) \% hydroxyl radical scavenging activity. Data expressed as mean \pm SD $(n=3, p<.001)$.

presence of divalent metal ions, such as iron and copper. The results obtained in this study demonstrate that EAF of seeds of SF had appreciable hydroxyl radical scavenging activity when compared with standard antioxidant BHT (Figure 2B) and could be served as anticancer agent by inhibiting the interaction of hydroxyl radical with DNA. The ability of the extracts to quench hydroxyl radicals might directly be related to the prevention of lipid peroxidation.

\section{Lipid peroxidation inhibition assay}

Reactive oxygene species induce membrane damage by peroxidising lipid moiety, specially the polyunsaturated fatty acids with a chain reaction known as lipid peroxidation [31]. The initial reaction generates a second radical, which in turn can react with a second macromolecule to continue the chain reaction leads to functional abnormalities of cells. Lipid peroxidation has been reported to be elevated in the cancer [32]. In this study, lipid peroxidation of mouse liver homogenates was induced by ferric ion plus ascorbic acid. The CME of seeds of SF and its four fractions especially EAF had appreciable lipid peroxidation inhibition activity (Figure 3). The SF extracts can prevent the cell abnormalities caused by cancer through breaking down of chain reactions responsible for lipid peroxidation. The lipid peroxidation inhibition by the EAF fraction was significantly correlated with hydroxyl radical scavenging (Figure 4). This result reveals that the extractives differentially inhibit lipid peroxidation by virtue of their varying degrees of free radical quenching potential. Thus, SF is a good source for antioxidant thereby can be used as anticancer agent.

\section{Effect of antioxidant on EAC-induced tumor cells}

Antioxidants neutralize free radicals, which is a natural by-product of normal cell processes. Free radicals are molecules with incomplete electron shells which make them more chemically reactive than those with complete electron shells. In humans, the most common form of free radicals is oxygen. When an oxygen molecule $\left(\mathrm{O}_{2}\right)$ becomes electrically charged or radicalized, it tries to steal electrons from other molecules, causing damage to the DNA and other molecules. Over time, such damage may become irreversible and lead to disease including cancer. Antioxidants are often described as "mopping up" free radicals, meaning they neutralize the electrical charge and prevent the free radical from taking electrons from other molecules thereby prevent cancer. Several laboratory evidences from chemical, cell culture and animal studies indicate that antioxidants may slow or possibly prevent the development of cancer [33]. In this study, the anticancer activity of EAF at low dose (below $25 \mathrm{mg} / \mathrm{kg}$ ) on EACinduced cancer in mice was not observed (data not

Table 2 Effect of EAF on EAC cell growth inhibition in mice (in vivo)

\begin{tabular}{lllll}
\hline Name of Exp. & $\begin{array}{l}\text { Nature of the } \\
\text { drug }\end{array}$ & $\begin{array}{l}\text { Dose } \\
\mathbf{m g} / \mathbf{k g} / \text { day (i.p) }\end{array}$ & $\begin{array}{l}\text { No. of EAC cells in mouse on day } \mathbf{6} \\
\text { after tumour cell inoculation }\end{array}$ & $\begin{array}{l}\text { \% of cell growth } \\
\text { inhibition }\end{array}$ \\
\hline $\begin{array}{l}\text { Control (EAC cell } \\
\text { bearing mice) }\end{array}$ & - & $(3.83 \pm 0.57) \times 10^{7}$ & - \\
Bleomycin & Standard & $0.3 \mathrm{mg} / \mathrm{kg}$ & $(0.62 \pm 0.05) \times 10^{7^{* *}}$ & 83.81 \\
EAF & Experimental & $25 \mathrm{mg} / \mathrm{kg}$ & $(1.9 \pm 0.21) \times 10^{7^{*}}$ & 50.39 \\
& & $50 \mathrm{mg} / \mathrm{kg}$ & $(1.25 \pm 0.11) \times 10^{7^{* *}}$ & 67.36 \\
\hline
\end{tabular}

Number of mice in each case $(n=6)$; the results were shown as mean \pm SEM. Where significant values are ${ }^{*} p<0.05$ and ${ }^{* *} p<0.01$ 
shown). Although the EAF inhibited the growth of cancer cells only at higher concentrations ( 25 and $50 \mathrm{mg} / \mathrm{kg}$ ), it exhibited comparable anticancer activity with bleomycin (Table 2), hence EAF might be a good source for isolating anticancer agent.

\section{Total phenolic, flavonoids, flavonols and proanthocyanidin contents}

Polyphenols are the most abundant antioxidants in the plant kingdom, and they have been claimed to have anti cancer property [34]. The antioxidant activity of the polyphenolic compounds is believed to be mainly due to their redox properties [35], which play an important role in adsorbing and neutralizing free radicals, quenching singlet and triplet oxygen or decomposing peroxides. Flavonoids are the most ubiquitious groups of plant secondary metabolites and have good antioxidant potential. Flavonoids have been shown to possess antimutagenic and antimalignant effect [36]. Furthermore, flavonoids have a chemopreventive role in cancer through their effect on signal transduction in cell proliferation and angiogenesis [37]. Dietary flavonols and proanthocyanidins in particular offer significant cardiovascular health benefits [38]. Proanthocyanidin-rich extract has preventive actions on diseases, such as atherosclerosis, gastric ulcer, large bowel cancer, cataracts and diabetes [39]. Results obtained in the present study revealed that the level of these phenolic compounds in seeds of SF were significant (Table 1). Our findings strongly suggest that the phenolics are important components of this plant, and some of its pharmacological effects like anticancer activity could be attributed to the presence of these valuable constituents.

\section{Conclusions}

The present study indicated that the ethyl acetate fraction of Syzygium fruticosum possessed the highest phenolic content than other fractions. Also, the EAF exhibited strong antioxidant and moderate anticancer activities, which were comparable to the commercial antioxidants BHT, CA and AA and the anticancer drug bleomycin. This seems that the Syzygium fruticosum extract can be used as natural antioxidant and anticancer agent. Further investigation is being carried out to identify and characterize the inherent phenolic compounds responsible for the antioxidant and anticancer activities from the ethyl acetate fraction of Syzygium fruticosum.

\footnotetext{
Abbreviations

AA: Ascorbic acid; AQF: Aqueous fraction; CAE: Catechin equivalent; CHF: Chloroform fraction; CME: Crude methanolic extract; DPPH: 1,1diphenyl-2-picrylhydrazine; EAC: Ehrlich's Ascites cells; EAF: Ethyl acetate fraction; GA: Gallic acid; GAE: Gallic acid equivalent; OS: Oxidative stress; PEF: Petroleum ether fraction; QE: Quercetin equivalent; ROS: Reactive oxygen species; RT: Room temperature; SF: Syzygium fruticosum; TAC: Total antioxidant capacity; TCA: Trichloro acetic acid.
}

Competing interests

The authors declare that they have no competing interests.

\section{Authors' contributions}

SI and SN, Designed the study and carried out the tests under the supervision of AHMKA. MAK, Carried out the lipid peroxidation inhibition assay. ASMSH, Helped to carry out the assay. Fl, Carried out the anticancer assay. PK, Checked the grammatical errors and corrected the final manuscript. NHM, Performed statistical (correlation and regression) analysis. MR, Helped to carry out the assay. GS, Helped to coordinate the biological assay and draft the manuscript. AAR, Helped to carry out the extraction process and prepare the manuscript. All authors read and approved the final manuscript.

\section{Acknowledgment}

The authors acknowledge the Department of Pharmacy, University of Rajshahi, Bangladesh for financial support. We also thank to Dr. AHM Mahabubur Rahman, Assistant Professor, Department of Botany, University of Rajshahi and National Herbarium, Dhaka, Bangladesh for the identification of the plant.

\section{Author details}

${ }^{1}$ Department of Pharmacy, University of Rajshahi, Rajshahi 6205, Bangladesh. Department of Pharmacy, Bangabandhu Sheikh Mujibur Rahman Science and Technology University, Gopalgonj 8100, Bangladesh. ${ }^{3}$ Department of Biochemistry and Molecular Biology, University of Rajshahi, Rajshahi 6205, Bangladesh. ${ }^{4}$ Department of Pharmaceutical and Biological Sciences, UCL School of Pharmacy, London, UK. 'Department of Statistics, University of Rajshahi, Rajshahi 6205, Bangladesh.

Received: 5 March 2013 Accepted: 17 June 2013

Published: 22 June 2013

\section{References}

1. Braca A, Sortino C, Politi M, Morelli I, Mendez J: Antioxidant activity of flavonoids from Licania licaniaeflora. J Ethno 2002, 79:379-381.

2. Maxwell SR: Prospects for the use of antioxidant therapies. Drugs 1995, 49:345-361

3. Willett WC: Balancing life-style and genomics research for disease prevention. Science 2002, 296:695-698.

4. Steinmetz KA, Potter DJ: Vegetables, fruit, and cancer prevention: a review. J Am Diet Asso 1996, 96:1027-1039.

5. Kahkonen MP, Hopia Al, Vuorela HJ, Rauha JP, Pihlaja K, Kujala KS: Heinonen: Antioxidant activity of plant extracts containing phenolic compounds. J Agr Food Chem 1999, 47:3954-3962.

6. Miliauskas G, Venskutonis PR, Beek TAV: Screening of radical scavenging activity of some medicinal and aromatic plant extracts. Food Chem 2004, 85:231-237.

7. Balasundram N, Sundram K, Samman S: Phenolic compounds in plants and agri-industrial by-products: Antioxidant activity, occurrence, and potential uses. Food Chem 2006, 99:191-203.

8. 2010, Elliot RW, Jones DL, Blake T: Encyclopaedia of Australian plants suitable for cultivation, volume 9. Australia: Port Melbourne: Lothian Press; 2010:160-161.

9. Ruan PZ, Zhang LL, Lin MY: Evaluation of the antioxidant activity of Syzygium cumini leaves. Mole 2008, 13:2545-2556.

10. Jain A, Sharma S, Goyal M, Dubey S, Jain S, Sahu J, Sharma A, Kaushik A: Anti-inflammatory activity of Syzygium cumini leaves. Int J Phytomed 2010, 2:124-126.

11. Singh N, Gupta M: Effects of ethanolic extract of Syzygium cumini (L.) seed powder on pancreatic islet of alloxan diabetic rats. Ind J Exp Bio 2007, 45:861-867.

12. Ravi K, Sivagnanam K, Subramanjan S: Antidiabetic activity of Eugenia jambolana seed kernels on streptozotocin induced diabetic rats. J Med Food 2004, 7:187-191.

13. Kasiappan R, Subbaih R, Subramanian S: Antihyperlipidemic effect of Eugenia jambolana seed kernel on streptozotocin induced diabetes rats. Food Chem Toxicol 2005, 43:1433-1439.

14. Muruganandan S, Srinivasan K, Chandra S, Tandan SK, Lal J, Raviprakash V: Anti-inflammatory activity of Syzygium cumini bark. Fitoterapia 2001, 72:369-375 
15. Khan MA, Rahman AA, Islam S, Khandokhar P, Parvin S, Islam MB, Hossain M, Rashid M, Sadik G, Nasrin S, Mollah MN, Alam AHMK: A comparative study on the antioxidant activity of methanolic extracts from different parts of Morus alba L. (Moraceae). BMC Res Notes 2013, 6:24. doi:10.1186/1756-0500-6-24.

16. Wolfe K, Wu X, Liu RH: Antioxidant activity of apple peels. J Agr Food Chem 2003, 51:609-614.

17. Ordonez AAL, Gomez JD, Vattuone MA, Isla MI: Antioxidant activities of Sechium edule (Jacq.) Swart extracts. Food Chem 2006, 97:452-458.

18. Kumaran A, Karunakaran RJ: In vitro antioxidant activities of methanol extracts of Phyllanthus species from India. LWT- Food Sci Technol 2007, 40:344-352.

19. Sun JS, Tsuang YW, Chen IJ, Huang WC, Hang YS, Lu FJ: An ultra-weak chemiluminescence study on oxidative stress in rabbits following acute thermal injury. Burns 1998, 24:225-231.

20. Prieto $P$, Pineda $M$, Aguilar $M$ : Spectrophotometric quantitation of antioxidant capacity through the formation of a phosphomolybdenum complex: specific application to the determination of vitamin E. Anal Bio 1999, 269:337-341.

21. Oyaizu M: Studies on products of browning reactions: antioxidant activities of products of browning reaction prepared from glucose amine. Jap J Nut 1986, 44:307-315.

22. Choi HY, Jhun EJ, Lim BO: Application of flow injectionchemilumineacence to the study of radical scavenging activity in plants. Phytother Res 2000, 14:250-253.

23. Klein SM, Cohen G, Cederbaum: Production of formaldehyde during metabolism of dimethyl sulphoxide by hydroxyl radical generating system. Biochem 1981, 20:6002-6012.

24. Liu F, Nagaki TB: Antioxidative and free radical scavenging activities of selected medicinal herbs. J Life Sci 2000, 66:725-735.

25. Sur P, Ganguly DK: Tea Plant Root Extract (TRE) as an Antineoplastic Agent. Planta Med 1994, 60:106-109.

26. Jayaprakasha GK, Girennavar B, Patil BS: Radical scavenging activities of Rio Red grapefruits and Sour orangefruit extracts in different in vitro model systems. Biores Tech 2008, 99:4484-4494.

27. Singh N, Rajini PS: Free radical scavenging activity of an aqueous extract of potato peel. Food Chem 2004, 85:611-616.

28. Duan $X, W u$ G, Jiang Y: Evaluation of the antioxidant properties of litchi fruit phenolics in relation to pericarp browning prevention. Mole 2007, 12:759-771

29. Li H, Wang X, Li Y, Li P, Wang H: Polyphenolic compounds and antioxidant properties of selected China wines. Food Chem 2009, $112: 454-460$.

30. Baumann J, Wurn G, Bruchlausen FV: Prostaglandin synthetase inhibiting 0-2 radical scavenging properties of some flavonoids and related phenolic compounds. Deutsche Pharmakologische Gesellschaft Abstracts of the 20th spring meeting, Naunyn-Schmiedebergs Abstract No: R27 cited in. Arch Pharmacol 1979, 307:R1-R77.

31. Scully C: Oral cancer: New insight into pathogenesis. Den Upd 1993, 4:95-98

32. Klauning JE XUY, Isenberg JS, Bachowski S, Kolaja KL, Jianga J, Stevenson DE, Waloorg EF Jr: The role of oxidative stress in chemical carcinogenesis. Envir Heal Persp 1998, 106:289-333.

33. Blot WJ, Li JY, Taylor PR, et al: Nutrition intervention trials in Linxian, China: supplementation with specific vitamin/mineral combinations, cancer incidence, and disease-specific mortality in the general population. J Natl Cancer Inst 1993, 85:1483-1491.

34. Lamoral-Theys D, Pottier L, Dufrasne F, Neve J, Dubois J, Kornienko A, Kiss R, Ingrassia L: Natural polyphenols that display anticancer properties through inhibition of kinase activity. Curr Med Chem 2010, 17:812-825

35. Zheng W, Wang SY: Antioxidant activity and phenolic compounds in selected herbs. J Agr Food Chem 2001, 49:5165-5170.

36. Fotsis T, Pepper MS, Aktas E, Breit S, Rasku S, Adlercreutz H: Flavonoid, dietary-derived inhibitors of cell proliferation and in vitro angiogenesis. Can Res 1997, 57:2916-2921.
37. Wagner H, Geyer B, Yoshinobu K, Govind SR: Coumestans as the main active principles of liver drugs Eclipta alba and Wedelica calendulaceae. Planta Med 1986, 5:370-372.

38. Scalbert A, Manach C, Morand C, Remesy C: Dietary Polyphenols and the Prevention of Diseases. Cri Rev Food Sci Nut 2005, 45:287-306.

39. Ariga T: The antioxidative function, preventive action on disease and utilization of proanthocyanidins. Bio Fact 2004, 21:197-201.

doi:10.1186/1472-6882-13-142

Cite this article as: Islam et al:: Evaluation of antioxidant and anticancer properties of the seed extracts of Syzygium fruticosum Roxb. growing in Rajshahi, Bangladesh. BMC Complementary and Alternative Medicine 2013 13:142.

\section{Submit your next manuscript to BioMed Central and take full advantage of:}

- Convenient online submission

- Thorough peer review

- No space constraints or color figure charges

- Immediate publication on acceptance

- Inclusion in PubMed, CAS, Scopus and Google Scholar

- Research which is freely available for redistribution 